\title{
A GOVERNANÇA DA ÁGUA: O CASO DOS COMITÊS DOS RIOS CHAPECÓ E IRANI - SC
}

\author{
Larissa de Lima Trindade ${ }^{1}$ \\ Luiz Fernando Scheibe ${ }^{2}$ \\ Wagner Costa Ribeiro ${ }^{3}$
}

Resumo: A governança da água é um importante instrumento de democratização e interação entre os entes públicos e privados na gestão integrada de recursos hídricos (GIRH). Neste sentido, este estudo objetivou analisar como está sendo desenvolvida a governança da água na Região Hidrográfica do Meio-Oeste Catarinense, a partir da aplicação de dois modelos de análise da governança da água. Para isso foram aplicadas entrevistas e questionários com 18 membros do Comitê das Bacias Hidrográficas dos Rios Chapecó e Irani. A análise local da governança da água evidenciou que este Grupo enfrenta muitas fragilidades, tais como: baixa participação dos membros e da sociedade civil, dificuldades e burocracia nos repasses financeiros, pouco conhecimento legal e técnico dos seus membros, ausência de utilização dos instrumentos previstos na Política Nacional de Recursos Hídricos.

Palavras-chave: Comitês de Bacias Hidrográficas; Gestão Hídrica; Governança da Água

\section{THE WATER GOVERNANCE: THE CASE OF COMMITTEES OF RIVERS CHAPECÓ AND IRANI - SC}

\begin{abstract}
Water governance is an important tool for democratization and interaction between public and private entities in the integrated management of water resources (IMWR). Therefore, this study points out how water governance has been developed in the Catarinense Midwestern Hydrographic Region, based on the application of two models of water governance analysis. For that, interviews and questionnaires were applied with 18 members of the Chapecó and Irani watershed Committee. The local analysis of water governance has shown that this group faces many weaknesses, such as low participation of members and civil society, difficulties and bureaucracy in financial transfers, lack of legal and technical knowledge of its members, lack of use of the instruments provided for in National Policy on Water Resources.
\end{abstract}

Keywords: Watershed Committees; Water Management.;Water Governance

\section{LA GOBERNANZA DEL AGUA: EL CASO DE LOS COMITÉS DE LOS RIOS CHAPECÓ E IRANI -SC}

Resumen: La gobernanza del agua es un importante instrumento de democratización e interacción entre los entes públicos y privados en la gestión integrada de recursos hídricos (GIRH). En este sentido, este estudio objetivó analizar cómo se está desarrollando la

\footnotetext{
1 Doutora em Ciências Humanas pela Universidade Federal de Santa Catarina, professora Adjunta da Universidade Federal da Fronteira Sul -UFFS - Campus Chapecó -SC. Email: larissa.trindade@uffs.edu.br

${ }^{2}$ Doutor em Ciências (Mineralogia e Petrologia) pelo instituto de Geociências da Universidade de São Paulo, professor titular emérito voluntário da UFSC. Email: scheibe2@gmail.com

3 Doutor em Geografia Humana pela Universidade de São Paulo, professor Titular do Departamento de Geografia, do Programa de Pós-Graduação em Geografia Humana e do Programa de Pós-Graduação em Ciência Ambiental da Universidade de São Paulo. Email: wribeiro@usp.br
} 
gobernanza del agua en la Región Hidrográfica del Medio Oeste Catarinense, a partir de la aplicación de dos modelos de análisis de la gobernanza del agua. Para ello se aplicaron entrevistas y cuestionarios con 18 miembros del Comité de Cuencas Hidrográficas de los Ríos Chapecó e Irani. El análisis local de la gobernanza del agua puso de manifiesto que este Grupo se enfrenta a muchas debilidades, tales como: baja participación de los miembros y de la sociedad civil, dificultades y burocracia en los traspasos financieros, poco conocimiento legal y técnico de sus miembros, ausencia de utilización de los instrumentos de la Política Nacional de Recursos Hídricos.

Palabras clave: Comités de Cuencas Hidrográficas; Gestión Hídrica; Gobernanza del Agua

\section{INTRODUÇÃO}

Segundo Jacobi e Sinisgalli (2012), o termo "governança" reflete o deslocamento de abordagens centradas no conceito de governo para um conceito mais abrangente, que incorpora os agentes não estatais. Por sua vez, Secchi (2009) esclarece que se trata de um modelo de gestão colaborativo de relação entre agentes estatais e não estatais na solução de problemas coletivos. Trata-se de um modelo de gestão horizontal democrático que pode auxiliar os países a melhorar suas condições econômicas e sociais.

Neste estudo, a interpretação de governança é derivada das ciências políticas e da administração pública, e deve ser entendida como um modelo horizontal de relação entre atores públicos e privados no processo de elaboração de políticas públicas (KOOIMAN, 1993; RICHARDS; SMITH, 2002).

Segundo Lima (2014), a governança pública envolve tanto a gestão administrativa do Estado, quanto a aptidão de articular e mobilizar os atores estatais e sociais para resolver problemas de ordem coletiva, ou seja, a governança pública é uma corrente da administração pública que procura compatibilizar os critérios de democratização com a busca pelo melhor desempenho das políticas públicas. Nesta perspectiva, cabe ao Estado o papel de liderar o processo de resolução dos problemas da coletividade, mas deve fazê-lo a partir da interação com a sociedade.

No âmbito dos recursos hídricos, entende-se por governança da água, o conjunto de aspectos políticos, sociais, econômicos e administrativos para desenvolver e gerenciar os recursos hídricos. Salienta-se que esta governança não envolve somente gestão hídrica, mas também tópicos relacionados ao saneamento básico, saúde, ordenamento do solo e preservação de recursos ambientais (AGÊNCIA NACIONAL DE ÁGUAS, 2011).

Segundo Jacobi (2009, p.28), a governança da água “...propõe caminhos teóricos e práticos alternativos que façam uma real ligação entre demandas sociais e seu diálogo em nível governamental". Para Ribeiro (2009, p. 114) é preciso identificar os "diversos sujeitos 
sociais que atuam em várias escalas de poder político [...], bem como a teia de relações multiescalares que repercutem no problema e no seu encaminhamento" (2009:114). Portanto, a governança exige a criação de leis, regulamentos e instituições, mas também perpassa por ações e políticas praticadas pelos governos e pelas sociedades locais e suas redes de influência. Desta forma, este estudo apresenta seguinte problema de pesquisa: como está sendo desenvolvida a governança da água na Região Hidrográfica do Meio-Oeste Catarinense (RH2)?

A analise se deu por meio de dois modelos- o modelo de Governança Multinível da Água, proposto pela Organização para a Cooperação e Desenvolvimento Econômico (OCDE, 2011) e o modelo proposto por Camargos (2008) ambos aplicados com os membros dos comitês das bacias hidrográficas $(\mathrm{CBH})$ dos Rios Chapecó e Irani. Salienta-se que a aplicação conjunta dos modelos - um internacional e outro nacional, permite uma visão mais completa das falhas e contribuições deste grupo para a gestão hídrica da água.

Destaca-se que o Comitê investigado é o órgão responsável direto pela promoção da gestão integrada, descentralizada e participativa na $\mathrm{RH} 2$, tendo sido implantado em 8 de setembro de 2010, através do Decreto Estadual n 3.498. Atualmente, ele é composto por 65 representantes, divididos em três grupos, a saber: representantes dos usuários da água (40\%), representantes da população da bacia hidrográfica (40\%) e representantes do poder público (20\%) (SANTA CATARINA, 2010).

Diante deste contexto a governança da água torna-se ainda mais relevante como ferramenta de auxílio na resolução de questões acerca de: disponibilidade hídrica, conflitos de uso e na sobreposição de instâncias decisórias na gestão do território de bacias hidrográficas. Ela pode ser uma alternativa que remete ao diálogo e à busca de entendimento em torno do acesso à água.

\section{A Gestão Integrada dos Recursos Hídricos e a Governança da Água}

Rahaman e Varis (2005) conceituam a gestão integrada como um processo que promove o desenvolvimento e a gestão coordenada da água, solo e recursos relacionados de uma forma mais equitativa entre os resultados econômico e a continuidade dos ecossistemas vitais. Para isso, os autores acreditam que a gestão integrada de recursos hídricos (GIRH) deve ocorrer, preferencialmente, na escala da bacia hidrográfica e sob os princípios de "boa governança" e participação pública. Por "boa governança", entende-se a forma, com regras claras e capacitação institucional, para que os governos diminuam incertezas e corrijam "falhas de mercado" (Rahaman; Varis, 2005). 
A partir deste conceito de "boa governança" é que Fracalanza, Jacob e Eça (2013), ao analisarem a GIRH aplicada no Brasil, criticam a gestão de recursos hídricos praticada no País, uma vez que esta não alcança a efetiva integração entre as políticas públicas de saneamento e recursos hídricos, bem como, não contribui para a redução das disparidades socioeconômicas para as populações de baixa renda. Os autores ressaltam que "[...] muitas vezes as políticas públicas relacionadas a recursos hídricos priorizam determinados usos que se relacionam à geração de valor pelo sistema capitalista, sem interface com os problemas distributivos do recurso a populações de baixa renda." (FRACALANZA; JACOB; EÇA, 2013, p. 30).

Castro (2007) analisa o conceito "governança da água no século XXI" e destaca que, para alguns, a governança é um instrumento, um meio para atingir certos fins, ou seja, um conjunto de ferramentas administrativas e técnicas que podem ser usadas em diferentes contextos para atingir um determinado objetivo, como a execução de uma política de água em particular. Para outros (HEINELT et al., 2002), a governança é instrumento que envolve não a implementação das decisões tomadas por um grupo de especialistas e tomadores de decisões, mas sim o debate de alternativas, a partir de projetos de desenvolvimento social, com a participação democrática substantiva.

Além das concepções contrastantes, alguns teóricos (GLOBAL WATER PARTNERSHIP, 2003) acreditam que as práticas de gestão da água devem ser estruturadas em torno dos princípios de que esta é um bem comum e que os serviços essenciais de água são um bem público que não pode ser regido pelo mercado. Há, no entanto, aqueles que defendem uma visão completamente oposta, que a água deve ser considerada como um recurso econômico e os serviços essenciais desta como um bem privado, em que a governança dos serviços de água deve ser centrada em princípios de mercado (HELD, 1995; HIRST, 1994).

Nesta perspectiva é que Castro (2007) acredita que a "crise da água" seja uma crise de governança, pois, infelizmente, a ausência de consenso teórico prejudica sua aplicação de forma global e atrasa a promoção de justiça social. Além disso, o autor argumenta que o componente central da governança da água é a participação democrática.

Ribeiro aponta que a governança depende de: "mobilização social, capacidade de assimilação do Estado de decisões externas a ele, criação ou existência de instrumentos jurídicos que possibilitem que a participação social ganhe legitimidade e acarrete em conseqüências aplicadas aos interesses dos grupos sociais que discutem o tema” (Ribeiro, 2009, p. 117-118). 
Para Jacobi e Sinisgalli (2012), a governança ambiental pressupõe a participação descentralizada, atuação em rede integrada e o ganho de poder dos atores envolvidos na gestão, interagindo como sujeitos ativos no processo de decisão. No entanto, destacam que, nas questões ambientais, os mecanismos de democracia deliberativa não têm incluído todos os atores sociais, o que tem provocado múltiplos conflitos socioambientais nos últimos anos, como problemas na construção de usinas hidrelétricas e obras de infraestrutura que afetam os cidadãos.

Para Campos e Fracalanza (2010), no Brasil, o processo de governança da água iniciou entre os anos 1970 e 1980, e se baseou na experiência francesa, tendo o papel do Estado como gestor exclusivo dos recursos naturais, e os descompassos entre oferta e demanda hídrica levaram ao desenho de um novo modelo de gestão. Este novo modelo deveria ser baseado em processos de negociação política e social, envolvendo diferentes níveis de governo e atores sociais. No entanto, os autores destacam que para que o modelo se efetive é necessário superar barreiras de articulação entre instâncias de gestão dos recursos hídricos e governos municipais, além de melhorar os canais de participação e comunicação dos agentes envolvidos na governança da água.

A gestão da água no Brasil foi definida em 1997, por meio da Lei n. 9.433, que criou a Política Nacional dos Recursos Hídricos (PNRH). Essa Lei prevê diversas ações, como a elaboração de um plano da bacia, o enquadramento dos corpos hídricos, a outorga do direito de uso, a cobrança pelo uso, a compensação aos municípios e a criação do Sistema Nacional de Gerenciamento de Recursos Hídricos (SINGREH), que congrega órgãos que devem implementar a PNRH.

\section{A Governança Multinível da Água (2011) e o Modelo proposto por Carmargos (2008)}

A Organização para a Cooperação e Desenvolvimento Econômico - OCDE (2011), a partir de estudos sobre a governança da água e suas falhas em trinta países (incluindo o Brasil), elaborou um Quadro de Governança Multinível da Água, que visa diagnosticar e superar as falhas envolvidas no processo de governança da água. Para a OCDE (2015), a Governança Multinível da Água é o compartilhamento explícito ou implícito da responsabilidade pela elaboração e implementação das políticas públicas entre diferentes níveis administrativos e territoriais (horizontalmente e verticalmente). Acredita-se que os governos que compartilham responsabilidades na formulação e implantação de políticas públicas, independentemente das características institucionais e organização do setor de recursos hídricos, enfrentam, em maior ou menor grau, sete categorias de lacunas (administrativa, política, financiamento, capacidade, objetivo, de responsabilização e 
informação) no gerenciamento de recursos hídricos que precisam ser diagnosticadas e reparadas.

A lacuna administrativa da governança da água, segundo a OCDE (2011), refere-se aos limites administrativos de cada ente no gerenciamento hídrico, à ausência de clareza de suas atribuições e, muitas vezes, à incompatibilidade de gerenciamento entre os limites administrativos e os limites hidrológicos levam muitos municípios, regiões, estados, agências e órgãos estaduais a não cooperarem ou a não participarem no gerenciamento hídrico.

No Brasil, este problema é ainda mais evidente devido ao duplo domínio e jurisdição sobre os rios estaduais e federais. Para a OCDE (2015), é preciso compatibilizar os limites administrativos e as fronteiras das bacias hidrográficas, tendo em vista que os impactos que acontecem em uma bacia refletem nas demais. Neste sentido, destaca-se o papel dos CBH como mecanismos para coordenar e auxiliar a preencher esta "lacuna administrativa", tendo em vista que os planos de bacias devem refletir políticas locais e integradas, portanto, é essencial que estes planos sejam efetivamente implantados.

A lacuna de política, segundo $\operatorname{OCDE}(2015$, p. 65), refere-se à “[...] fragmentação das tarefas relacionadas à água entre os ministérios e órgão públicos em nível nacional e entre autoridades locais e regionais do nível subnacional [...]”, o que resulta, especialmente no Brasil, em políticas públicas fragmentadas e desconexas. São exemplos desta realidade, a política de gestão dos recursos hídricos e a política de uso e ocupação do solo que não conversam entre si, e o mesmo problema ocorre com a política de saneamento básico. Neste sentido, faz-se necessário um planejamento integrado entre os ministérios e os níveis de governo, no intuito, principalmente, de transpor as inconsistências e minimizar as contradições nestas legislações.

A lacuna de financiamento diz respeito ao descompasso financeiro, entre os ingressos de recursos financeiros e os dispêndios no setor hídrico. De acordo com a OCDE (2015), o valor necessário de recursos financeiros até 2033 para serviços de água e esgoto pode vir a representar 5,2\% do PIB Brasileiro. Sem uma estimativa de financiamento e compromissos estáveis de longo prazo, a política de recursos hídricos não poderá ser implementada com êxito. É importante maximizar os recursos disponíveis e atrair financiamento adicional, o que requer acordos entre governos federal, estaduais e municipais. Além disso, é preciso assegurar que os fundos sejam gastos de modo otimizado. De outra forma, o gasto inadequado não apenas prejudicará a implementação, mas também coloca em risco a realização das metas de crescimento e bem-estar. Salienta-se que a aplicação do instrumento de cobrança pelo uso da água pode auxiliar a superar esta lacuna, no entanto, é importante que este instrumento seja 
bem implantado, avaliado e que seus resultados possam ser efetivamente aplicados na gestão hídrica local (OCDE, 2015).

Incapacidade técnica, científica e de infraestrutura para formular e implementar as políticas de recursos hídricos compõem a "lacuna de capacitação", especialmente, em países que descentralizaram sua gestão. Para Organização para a Cooperação e Desenvolvimento Econômico (OCDE 2015, p. 77), a descentralização da gestão de recursos hídricos no Brasil é um "[...] assunto inacabado, tendo em vista que as responsabilidades foram transferidas de direito, mas não conseguiram ser implantadas de fato." Capacitar tecnicamente, cientificamente e com infraestrutura adequada, especialmente, as instituições estaduais e locais, é essencial para a consolidação da PNRH.

Já a lacuna de objetivo ocorre quando existem objetivos divergentes, entre os níveis de governo e órgãos públicos, que comprometem os objetivos de longo prazo da política de recursos hídricos. A descontinuidade das políticas públicas, devido à alternância dos governos, agrava ainda mais esta lacuna. Segundo a OCDE (2011), uma estratégia para minimizar este problema é trabalhar na perspectiva de construir consenso em torno das condições dos recursos hídricos, mobilizando a sociedade e profissionais especializados no assunto, independentemente de sua preferência política.

A sexta lacuna proposta pela OCDE (2011) refere-se à responsabilidade e diz respeito à falta de transparência e abrangência na elaboração das políticas voltadas aos recursos hídricos. No Brasil, uma alternativa para reduzir esta lacuna foi proposta pela ANA em 2011, a partir da criação do Pacto Nacional pela Gestão das Águas. Este Pacto representa um instrumento para melhorar a integração entre os sistemas de recursos hídricos nacionais e estaduais, e visa reduzir as discrepâncias regionais de governança da água, por meio da criação de metas de gestão, que, se atendidas, resultam no repasse de recursos financeiros aos estados (OCDE, 2015). Todos os estados brasileiros assinaram este Pacto e estabeleceram metas de gestão que devem ser atingidas em cinco anos, a contar da data de assinatura do decreto que institui o Pacto entre o estado e a União.

Por fim, a lacuna de informação refere-se à ausência ou assimetria de informação entre os níveis de governo, órgãos públicos e atores locais envolvidos na política de recursos hídricos. Esta lacuna resulta, principalmente, na dificuldade de promover melhorias nas políticas públicas e é fruto da incapacidade técnica, de infraestrutura, administrativa e científica das instituições e dos gestores públicos nesta área, conforme já discutido na lacuna de capacitação. Observa-se que a ausência de compartilhamento e acompanhamento das informações obtidas provoca discrepância de informações, o que ocorre muito nos bancos de 
dados sobre informações hídricas nos níveis federal e estadual, e prejudica significativamente o avanço dos sistemas de gerenciamento hídrico.

No geral, os governos estaduais tendem a ter mais informações que os governos nacionais sobre as realidades, necessidades e custos locais de cada bacia hidrográfica; neste caso, a menos que eles gerem e publiquem estas informações em tempo oportuno e em nível central, prevalecerá a lacuna de informação. Desta forma, cabe ao governo central (União) desempenhar um papel de gestor da informação, exigindo que os governos estaduais repassem as informações para que sejam parte de um banco de dados nacional e que realmente reflita a realidade de cada bacia hidrográfica. Isto é muito importante para aquelas bacias hidrográficas que tem suas terras em mais de um estado da Federação. Observa-se que as informações também podem ser usadas para identificar as necessidades de capacitação, e, mais uma vez, verifica-se a relação de dependência mútua das "lacunas", em que uma pode desencadear a outra e ao mesmo tempo o preenchimento de uma pode resultar no melhoramento da outra.

Objetivando avaliar a governança pública da água nas bacias hidrográficas do estado de Minas Gerais, Camargos (2008) elaborou, a partir da escala global de governança pública proposta pela OCDE (2005), quatro dimensões de análise da governança local da água. A primeira dimensão refere-se a ações que assegurem uma estrutura jurídica e regulatória efetiva, sendo que o objetivo desta dimensão é verificar, a partir da percepção dos atores sociais diretamente envolvidos no processo de gestão, se a legislação apresenta conteúdo claro, flexível e transparente. A segunda dimensão proposta por Camargos (2008) diz respeito à análise das ações do Estado, enquanto principal responsável pela gestão de recursos hídricos, e visa verificar o nível clareza, transparência, prestação de contas e profissionalismo na gestão de recursos hídricos executada pelos estados. A terceira dimensão proposta por Camargos (2008) refere-se à análise das ações relacionadas à interação entre o Estado e os demais envolvidos na gestão dos recursos hídricos (stakeholders), além de verificar o nível de transparência e divulgação das informações; nesta dimensão, sete aspectos devem ser ponderados e visam, entre outras coisas, verificar o nível de cooperação e comunicação entre o Estado e os demais stakeholders. A última dimensão proposta pela autora envolve o papel dos conselhos, e, em especial neste estudo, dos $\mathrm{CBH}$, na governança local da água; esta dimensão visa avaliar a autoridade, competência e objetividade destes organismos de gestão.

\section{Metodologia}

A fim de atender ao objetivo geral desta pesquisa foi realizado um estudo de caso único com membros do Comitê Gestor das Bacias Hidrográficas dos Rios Chapecó e Irani, conforme propõe Yin (2010). 
Como técnicas de coleta de dados, foram realizadas entrevistas com os membros do Comitê Gestor das Bacias Hidrográficas dos Rios Chapecó e Irani, observações durante as reuniões da diretoria e das Assembleias realizadas durante os anos de 2013 e 2014, e análise documental de todas as atas, pareceres e documentos produzidos pelo referido Comitê desde sua criação em 2010 até o ano de 2015 (31 atas e 1 parecer). As entrevistas tinham como intuito levantar todo o processo de criação e participação dos referidos membros no Comitê, bem como, o de verificar as percepções acerca das contribuições deste Comitê à GIRH e à governança da água no Meio-Oeste Catarinense. Com as observações in loco dos trabalhos do Comitê foi possível também acompanhar as ações e ferramentas desenvolvidas ao longo dos anos de 2014 e 2015 e acompanhar todo o processo de participação dos membros no Comitê. Também a técnica de análise documental permitiu levantar todas as ações produzidas pelo Comitê nestes cinco anos de existência.

Participaram da entrevista 18 membros do Comitê, ou seja, com 27,69\% dos 65 membros efetivos do Comitê, incluindo cinco representantes do Poder Público Estadual (PPE), dois representantes do Poder Público Federal (PPF), cinco representantes dos usuários da água (UA) e seis representantes da Sociedade Civil Organizada (SCO). Desta forma, participaram das entrevistas representantes das três categorias que formam o Comitê, conforme determina a Resolução n. 03/1997 do Conselho Estadual de Recursos Hídricos de Santa Catarina.

Salienta-se que as entrevistas com os membros se estenderam até o limite da saturação ou esgotamento do tema, conforme propõe Minayo (2004). O roteiro de entrevista foi adaptado do modelo proposto inicialmente pela Organização para a Cooperação e Desenvolvimento Econômico (2005) e validado na gestão de recursos hídricos por Camargos (2008).

Salienta-se que o Modelo da OCDE (2005) avalia o gerenciamento hídrico a partir de sete lacunas (administrativa, política, financiamento, capacidade, objetivo, de responsabilização e informação) já o Modelo de Carmargos (2008) propõe-se a avaliar a governança local da água a partir de quatro dimensões: estruturas jurídicas; ações do Estado; interações entre as partes relacionadas e papel dos atores sociais.

Para a análise dos dados coletados, recorreu-se à Análise de Temática proposta por Bardin (2014), que constitui um conjunto de técnicas de análise das comunicações visando obter a descrição do conteúdo das mensagens (falas dos participantes do estudo), permitindo a inferência de conhecimentos relativos às variáveis do estudo. 
No intuito de auxiliar na análise, utilizou-se o software Atlas Ti 7.0 (Qualitative Research and Solutions). Este software auxilia o pesquisador a gerenciar, a classificar e a vincular as informações em níveis de abstração, facilitando, desta forma, a organização dos dados em categorias e famílias.

Ainda, foi feita a análise quantitativa dos resultados das questões objetivas que compõem o roteiro de entrevista, visando levantar as percepções dos membros que compõem o Comitê das Bacias Hidrográficas pesquisadas acerca da: i) estruturação jurídica e regulatória da gestão de recursos hídricos; ii) ações do Estado enquanto gestor do bem coletivo; iii) relacionamento com os stakeholders, transparência e divulgação de informações; e iv) o papel do comitê. Neste bloco, os entrevistados poderiam dar notas de 0 a 7 para as afirmações, onde 0 representava discordância total e 7 , concordância total com a afirmação. As notas dadas foram ponderadas, sendo que: entre 0 a 3 estavam no grupo de maior discordância, a nota 4 foi considera neutra e as notas de 5 a 7 estavam no grupo de maior concordância, segundo é proposto por Camargos (2008). Os dados objetivos obtidos foram digitados e tabulados no Excel 2010 e submetidos a tratamento estatístico utilizando-se o software Statistical Package for the Social Sciences (SPSS), versão 21.10; foram utilizadas tabelas de distribuição de frequências absolutas e percentuais, medidas de tendência central.

\section{O CBH dos Rios Chapecó e Irani: a experiência no Oeste Catarinense}

Segundo o último censo do Instituto Brasileiro de Geografia e Estatística (2010), o estado de Santa Catarina possuía uma população de 6.248.436 habitantes, distribuídos em seis mesorregiões: Mesorregião da Grande Florianópolis, Mesorregião Norte Catarinense, Mesorregião Serrana, Mesorregião do Sul Catarinense, Mesorregião do Noroeste Catarinense e Mesorregião do Oeste Catarinense. Esta última possui uma área de aproximadamente 27.288.763 $\mathrm{Km}^{2}$ e conta com uma população superior a 1.200.000 habitantes. É formada pela união de 117 municípios agrupados em cinco microrregiões: Microrregião de Chapecó, Microrregião de Concórdia, Microrregião de Joaçaba, Microrregião de São Miguel do Oeste e Microrregião de Xanxerê.

A Mesorregião do Oeste Catarinense é berço de algumas das maiores empresas do ramo alimentício da América Latina, tais como BR Foods (Sadia e Perdigão), Aurora e Seara, e possui cidades de pequeno e médio porte com infraestrutura viária, indústria e comércio. Suas principais atividades econômicas são agroindústria e agropecuária, focada, principalmente, na suinocultura e avicultura, e processamento de seus produtos. Hidrograficamente, é banhada pelo Rio Uruguai e seus afluentes, como os Rios Pelotas, Canoas, do Peixe, Chapecó, Irani, todos pertencentes à Bacia Hidrográfica do Rio Uruguai (IBGE, 2010). 
Na Figura 1 apresenta-se o território de gestão do Comitê das Bacias Hidrográficas dos Rios Chapecó e Irani. A população deste território é de aproximadamente 609.304 habitantes e as principais atividades desenvolvidas neste território são a criação e o processamento de suínos e aves.
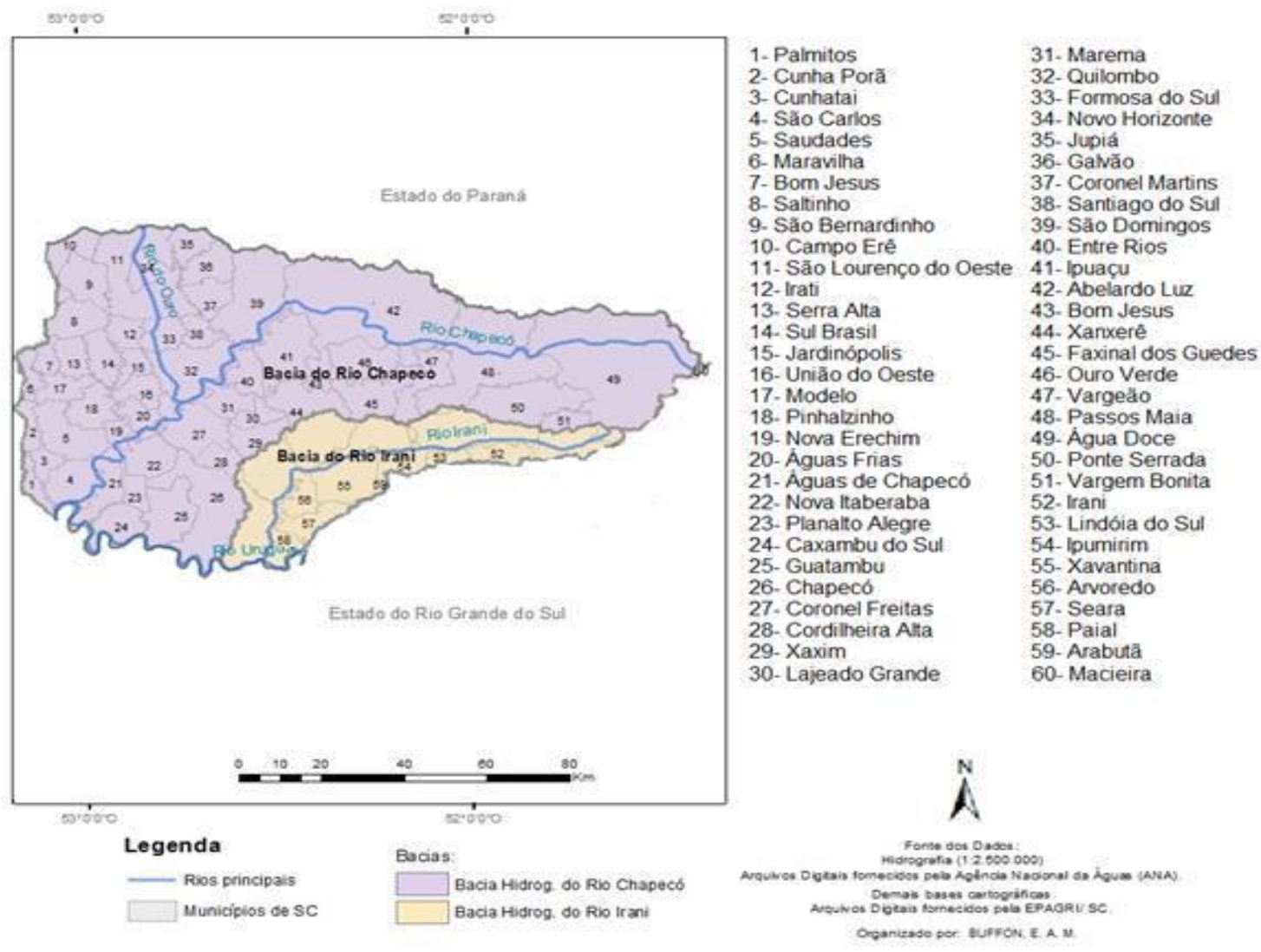

Figura 1 - Território de gestão do Comitê das Bacias Hidrográficas dos Rios Chapecó e Irani Fonte: própria, adaptada da Agência Nacional de Águas (2010) e da Empresa de Pesquisa Agropecuária e Extensão Rural de Santa Catarina (EPAGRI, 2010).

O Comitê das Bacias Hidrográficas dos Rios Chapecó e Irani surgiu a partir de uma iniciativa do governo do estado de Santa Catarina em parcerias com entidades estaduais. Em especial deve-se ressaltar a atuação do escritório local da CASAN (Companhia Catarinense de Águas e Saneamento) que forneceu os primeiros técnicos para fomentar as discussões na região do Meio-Oeste Catarinense, e que propôs a criação de um pré-comitê. Este pré-comitê iniciou suas discussões em 2000, com a realização de diversos eventos (audiências públicas) para mobilizar as organizações e as comunidades locais para a criação de um possível CBH na Região do Meio-Oeste do Estado. No entanto, o Decreto Oficial de criação somente ocorreu dez anos depois - Decreto Estadual n. 3.498, de 8 de dezembro de 2010 -, em que este Comitê só foi instalado efetivamente em 24 de março de 2011, com a eleição da primeira diretoria. 
Em 2015, o Comitê das Bacias Hidrográficas dos Rios Chapecó e Irani contava com 65 membros, no entanto, esta pesquisa constatou, a partir das atas das reuniões, das entrevistas, da participação nas assembleias, reuniões e oficinas promovidas pelo referido Comitê, que apenas cerca de $50 \%$ dos membros atuavam ou participavam ativamente ${ }^{4}$. Salienta-se que este Comitê já passou por duas gestões e por várias mudanças na composição de seus membros e/ou instituições, e esta alternância de membros e a baixa participação constituem-se em problemas graves para a governança da água, cujo participação é fundamental.

A fim de melhor analisar as ações e o desenvolvimento do "Comitê Chapecó/Irani", como é chamado pelos seus membros, foram realizadas entrevistas com 18 deles, que participam frequente e ativamente do Comitê, e que representavam segmentos diferentes dentro deste. Dentre os 18 entrevistados, $27,8 \%(n=5)$ representavam o segmento PPE; 11,1\% $(n=2)$, representavam o segmento PPF; $27,8 \%(n=5)$, do segmento UA; e 33,3\% (n=6) pertenciam ao segmento SCO.

Acerca do perfil dos entrevistados, pode-se destacar um grau de formação escolar elevado, em que todos os membros entrevistados possuem ensino superior completo, alguns possuem especialização (4/22,2\% membros) e outros, mestrados (3/16,7\% membros). Em média, o tempo de serviço na instituição que representa dentro do Comitê também se mostra elevado, em torno de dez anos, variando entre 1 e 29 anos de trabalho (amplitude). Acerca da experiência dentro do Comitê, observa-se que a maioria dos entrevistados $(n=11 / 61,1 \%)$ participam do Comitê desde sua fundação em 2010, alguns participaram inclusive do período "pré-comitê". Dos que participam mais recentemente $(n=4 / 22,2 \%)$, todos têm pelo menos um ano de experiência no Comitê.

As entrevistas com os membros revelaram que o Comitê apresenta muitas dificuldades para realizar ações/deliberações efetivas, percepção que foi destacada tanto pelos membros mais antigos quanto atuais. Para melhor analisar as fragilidades relatadas pelos participantes, que impactam diretamente na eficácia do Comitê, estas foram categorizadas em 15 categorias, sendo que a fragilidade que mais apareceu nas fala dos membros (16 vezes de um total de 18 entrevistas) foi a Fragilidade 2: "Ausência de participação efetiva dos membros", e representa um problema para todos os segmentos do Comitê.

Outra fragilidade muito destacada (15 vezes) pelos membros entrevistados foi a Fragilidade 4: "Dificuldade e burocracia no repasse dos recursos financeiros". Para os entrevistados, muitas das dificuldades de atuação do Comitê são relativas à existência de

\footnotetext{
4 Por ativamente considerou-se membros que não apenas comparecem às assembleias, mas que também participam das reuniões das câmaras técnicas, da diretoria, das oficinas e das capacitações promovidas pelo Comitê.
} 
muita burocracia e dificuldades no repasse dos recursos financeiros, isto porque os CBH não podem receber os recursos financeiros diretamente, por serem órgãos sem personalidade jurídica; sendo assim, necessitam de uma instituição parceira, capaz de assinar convênio com o governo estadual para receber e prestar contas dos recursos financeiros repassados. Além deste problema, os membros reclamam que, costumeiramente, o dinheiro disponibilizado é repassado com atraso, devendo as ações de operacionalização ser desenvolvidas no prazo máximo de um ano, o que dificulta sua aplicação com maior presteza e provoca, em alguns casos, a devolução do recurso financeiro. A pouca participação da sociedade civil também é um ponto negativo neste Comitê (Fragilidade 11) e foi destacada por 14 membros.

A "não utilização dos instrumentos previstos na PNRH na Região Hidrográfica 2" (Fragilidade 10) e a "falta de apoio do governo do estado" (Fragilidade 1) também foram destacadas pelos entrevistados (11 e 10 vezes, respectivamente). Os entrevistados também ressaltaram o pouco conhecimento técnico de alguns membros do Comitê como um problema importante (este problema foi mencionado em nove falas), especialmente, porque alguns apresentam dúvidas a respeito de qual é o real papel de um comitê de bacia hidrográfica e outros possuem dificuldades para compreender a legislação ou mesmo emitir determinadas opiniões sobre assuntos mais técnicos. Ter clareza sobre o real papel dos CBH (deliberativo e consultivo) entre os membros representa uma medida emergente e prioritária nas ações da diretoria, a fim de que este Comitê possa amadurecer e melhor decidir sobre os conflitos de água. Também contribuirá para reduzir outra fragilidade diagnosticada neste estudo, a Fragilidade 3: "Ausência de difusão e empoderamento do Comitê".

Para 50\% dos membros entrevistados, o Comitê das Bacias Hidrográficas dos Rios Chapecó e Irani não possui difusão junto à sociedade e por isso não é reconhecido pelos órgãos públicos e pela sociedade como ente decisório na gestão hídrica da RH2.

Observa-se que as fragilidades mais frequentes neste Comitê correspondem às mencionadas na literatura (TRINDADE, 2016; GAGG, 2014; FRACALANZA; JACOB; EÇA, 2013; MACHADO, 2012; JACOBI e SINISGALLI, 2012; OLIVEIRA, 2011; PEREIRA; MEDEIROS, 2009; RIBEIRO, 2009; GOMES, 2008; MOREIRA, 2008; CASTRO, 2007; MADRUGA, 2007) e afetam significativamente a consolidação e os trabalhos dentro dos CBH brasileiros.

Salienta-se que as fragilidades identificadas estão diretamente relacionadas ao "vício" do governo brasileiro em elaborar legislações, especialmente, as relacionadas ao meio ambiente, que existem apenas na teoria, sendo muito pouco implantadas na prática. Acreditase que para superar estas fragilidades é necessário criar um programa amplo de apoio ao $\mathrm{CBH}$ 
brasileiros, que preveja incentivos financeiros consistentes, sobretudo, para a consolidação dos instrumentos da PNRH e para a criação das agências de bacias, apoio técnico e educacional, a fim de que estes sejam realmente capacitados para serem instâncias deliberativas.

Apesar de todas estas fragilidades, sete avanços foram mencionados por pelo menos um membro entrevistado, são eles: Avanço 1 - Melhoramento do regimento e criação das câmaras técnicas e de apoio multidisciplinar; Avanço 2 - Melhoramento das discussões sobre o Plano de Bacia do Rio Chapecó; Avanço 3 - Melhorias na gestão do Comitê; Avanço 4 Divulgação e articulação institucional do Comitê; Avanço 5 - Aumento da motivação dos membros; Avanço 6 - Melhoria na participação social; e Avanço 7 - Promoção da educação ambiental na Bacia.

Conforme a frequência dos codes, identificou-se que o Avanço 4, aumento da divulgação e da articulação institucional do Comitê, foi o mais mencionado pelos membros do Comitê. Para 12 dos entrevistados, este melhorou, significativamente, a partir da segunda gestão do Comitê. Conforme as falas, o Comitê tem trabalhado mais na sua divulgação para a sociedade, através de palestras e eventos, visando chamar a comunidade a participar das ações. Outro avanço que foi mencionado em pelo menos seis falas de entrevistados foi o relacionado ao melhoramento na gestão e organização do Comitê (Avanço 3), especialmente, a partir da segunda gestão. Acerca disso, e sendo o Comitê um CBH bastante novo no Estado de Santa Catarina, com apenas duas gestões, pode-se observar que a organização da primeira diretoria não foi considerada boa pelos membros e poucos dados à respeito desta gestão foram obtidos (apenas quatro atas, conforme discutido à frente); isto pode ter ocorrido em função da falta de apoio técnico, financeiro e operacional do governo do Estado.

Também foram destacados como avanços: a promoção da educação ambiental nas Bacias Hidrográficas (Avanço 7), através de ações voltadas para a educação de jovens, crianças e adultos; o melhoramento do regimento; e a criação de câmaras técnicas dentro do Comitê (Avanço 1).

A partir do mapeamento das fragilidades e dos avanços destacados pelos membros entrevistados neste Comitê, observa-se que estes vão ao encontro das fragilidades e contribuições encontrados na literatura e revelam que se por um lado os CBH contribuem para a promoção da educação ambiental nas bacias hidrográficas e na ampliação de maiores espaços participativos, por outro lado, na prática, no Brasil, os comitês de modo geral estão afastados de seu principal objetivo, que é o de ser um parlamento de águas, ou seja, um local 
onde decisões devem ser discutidas, ponderadas, analisadas e deliberadas sempre no intuito de melhorar a governança local dos recursos hídricos.

Destaca-se também, a partir dos resultados emergidos com a aplicação da Matriz Multinível de Governança da Água, proposta pela OCDE (2011) em nível local, ou seja, na gestão do Comitê das Bacias Hidrográficas dos Rios Chapecó e Irani, que estão presentes, além da lacuna administrativa - devido às dificuldades de clareza sobre o real papel dos $\mathrm{CBH}$, a lacuna de financiamento, pois o referido Comitê ainda enfrenta problemas de repasse de recursos financeiros e não conta com uma agência de bacia para realizar os trabalhos executivos e financeiros.

Além disso, outra lacuna que se mostra bastante presente no nível local é a da capacidade, relacionada com a "incapacidade do referido Comitê em se legitimar como um órgão efetivamente deliberativo, onde decisões a respeito dos recursos hídricos são tomadas e acatadas pelo governo do estado de Santa Catarina", o que corrobora o argumento de Ribeiro (2009, p. 114), que aponta a dificuldade de conferir "legitimidade dos interlocutores bem como do sistema de discussão do problema que os afeta para alcançar uma solução conjunta e duradoura" como um dos impasses da governança da água no Brasil. Por fim, a lacuna de informação também pode ser identificada dentro deste Comitê, que, devido às demais lacunas e às próprias fragilidades ponderadas por seus membros, acaba por não produzir informações relevantes a respeito das Bacias Hidrográficas as quais tem responsabilidade compartilhada em gerenciar, gerando, desta forma, também a lacuna de responsabilidade.

De modo geral, o que se observa é que o Comitê das Bacias Hidrográficas dos Rios Chapecó e Irani trabalhou nestes cinco primeiros anos de existência, principalmente, na sua estruturação. Durante este período, o Comitê não desenvolveu ações de deliberações, e nem mesmo conseguiu atuar no plano de ação estabelecido desde 2012. A leitura das atas evidencia que este Comitê não tem conseguido desenvolver sua principal função - que é de ser um "parlamento de águas na RH2" -, tendo em vista que nenhuma decisão ou deliberação até agora foi tomada por este Comitê. Salienta-se que a inexistência de ações efetivas prejudica a continuidade das atividades desenvolvidas pelo Comitê, especialmente porque, além de desestimular a participação dos membros nas reuniões e assembleias, enfraquece o Comitê diante do governo e da sociedade.

Por fim, no intuito de avaliar a percepção dos membros deste Comitê quanto à Governança da Água, sobretudo, a desenvolvida no estado de Santa Catarina e na RH2, aplicou-se o modelo proposto por Camargos (2008). 
No que se refere à primeira dimensão proposta pela autora, que trata das estruturas jurídicas, ou seja, da legislação como um todo, foi observado que, para $61,11 \%$ dos membros entrevistados, a legislação nacional é clara no seu conteúdo, no entanto, para 38,89\% dos entrevistados a legislação não é muito clara, principalmente "para a sociedade em geral". Costa (2008) destaca a necessidade de se criar uma política participativa que não apenas transfira as responsabilidades públicas às esferas civis, mas que possibilite que pessoas comuns sejam capazes de entender e decidir sobre questões que afetam suas vidas, sendo assim necessário capacitá-las para compreender estas legislações.

Também foi questionado se as obrigações e responsabilidades de cada órgão gestor de recursos hídricos encontram-se bem definidas. Para 55,56\% dos respondentes, as responsabilidades e obrigações não estão claramente definidas, principalmente, em nível estadual. Também, para $81,33 \%$ dos entrevistados, estas obrigações e responsabilidades não são divulgadas, o que prejudica compreender "a quem cabe o que na gestão das águas". Os participantes do estudo também destacaram que estas obrigações e responsabilidades no estado de Santa Catarina permanecem apenas no campo do discurso e não na prática diária.

Para Camargos (2008), uma das possíveis razões para a falta de transparência na divulgação das informações e nas responsabilidades é a complexa estrutura da gestão de recursos hídricos, que contempla diversas instâncias como órgãos outorgantes, órgãos coordenadores estaduais e federais e diferentes organismos deliberativos.

Dos entrevistados, $76,5 \%$ consideram que a legislação vigente não permite flexibilidade para ajustes na estrutura de capital dos órgãos gestores de água para que se alcancem os objetivos previstos na Política Estadual de Recursos Hídricos, principalmente, para os CBH. Nesta perspectiva é que os entrevistados destacaram a dificuldade de operacionalização dos CBH em Santa Catarina. Este dado também corrobora com o estudo realizado por Madruga (2007) com os CBH catarinenses. Neste tópico, ficou evidenciada nos comentários a falta de autonomia administrativa e financeira dos $\mathrm{CBH}$, bem como, ausência de estrutura e capacidade operacional, principalmente, em função da inexistência das agências de bacias no Estado, o que contribui para dificultar a busca por investimentos no setor de recursos hídricos.

Sobre a segunda dimensão do Modelo proposto por Camargos (2008), que visa avaliar o profissionalismo e a eficácia das ações dos Estados como responsáveis pela gestão de recursos hídricos, os membros foram questionados, inicialmente, se o Estado apresenta um quadro claro, coerente e transparente de sua política de águas. Para 60\% dos entrevistados, o Estado não apresenta um quadro conforme preconizado, além de estar atrasado com relação à cobrança, ao plano estadual de recursos hídricos e à criação das agências de bacias. 
Muitos dos entrevistados $(55,55 \%)$ não acreditam que informações sobre recursos hídricos sejam frequentemente apresentadas e discutidas nos órgãos legislativos e de auditoria dentro do Estado. Destacaram que os órgãos legislativos estaduais e municipais atuaram no início, mas agora, na implantação da Política Estadual de Recursos Hídricos, eles "sumiram do processo". Para 68,80\% dos entrevistados, o estado de Santa Catarina não possibilita autonomia decisória para os $\mathrm{CBH}$, tendo em vista que "as decisões sobre recursos hídricos não estão sendo repassadas aos $\mathrm{CBH}$, que acabam sendo excluídos do processo decisório" (PPE 1), sendo este o comentário mais destacado pelos membros nesta questão.

Em relação ao processo de avaliação de desempenho e ao sistema de informação utilizado pelo Estado, para $80 \%$ dos membros entrevistados, estes não podem ser considerados eficazes, tendo em vista que não existem indicadores de desempenho sobre a gestão hídrica no Estado e o Sistema de Informações Hídricas Estadual; ou, apesar de existir, segundo os membros: "não refletem dados reais sobre as bacias hidrográficas, tendo em vista que apresentam dados defasados e sob determinados aspectos nem dados possuem" (UA 3). Estas falas corroboram com os dados encontrados em Madruga (2007).

O modelo de Governança da Água proposto por Camargos (2008) também objetiva avaliar as interações que ocorrem entre o Estado e as demais partes envolvidas na GIRH, sobretudo, no tocante à transparência e à comunicação, tendo em vista que são princípios básicos da boa governança (OCDE, 2015a). Neste sentido, foi questionado aos entrevistados se o órgão gestor (Estado) assegura direitos a todas as partes interessadas na gestão de recursos hídricos. Para $72 \%$ dos entrevistados, o Estado assegura direitos iguais, tendo em vista que "as partes interessadas então sendo representadas dentro dos Comitês a partir do percentual estabelecido pela Política Estadual de Recursos Hídricos" (PPE 1). Porém, para $28 \%$ dos entrevistados, algumas partes interessadas são "privilegiadas" em detrimento de outras, especialmente, os representantes da sociedade civil, que pouco atuam, por vezes, em função do "pouco conhecimento que detêm sobre determinados aspectos da gestão de águas" (SCO 7).

Para os entrevistados, tendo em vista que o Comitê não tem recebido demandas para deliberar sobre nenhum conflito da água, é extremamente difícil avaliar se todas as partes interessadas possuem garantias e condições equânimes nas reuniões e nas decisões. Este fato contribui para que $76,5 \%$ dos entrevistados julguem como baixo o nível de transparência e comunicação do Estado com seus stakeholders. Os participantes destacaram que não tiveram contato com os relatórios das ações desenvolvidas pelo Estado no âmbito da RH2. 
Para Camargos (2008), os estados têm dificultado o repasse de decisões que preveem a participação dos $\mathrm{CBH}$, porque questionam sua capacidade técnica para decidir; no entanto, para a autora, os CBH são os organismos mais indicados para a promoção do debate e representatividade das partes interessadas. A contestação da operacionalização dos $\mathrm{CBH}$ gira em torno das dificuldades administrativas de coordenar os diversos interesses e da própria composição e habilidades necessárias aos integrantes de um $\mathrm{CBH}$, contudo, essas dificuldades somente serão superadas na medida em que estes exercitarem seu poder e aplicarem suas atribuições.

A última dimensão proposta pelo modelo de Camargos (2008) avalia o papel do CBH. Neste item foram apresentadas sete afirmativas aos membros entrevistados. A primeira delas questionava se era garantido ao Comitê independência para exercer suas responsabilidades, sendo que para $61,10 \%$ dos entrevistados esta independência não é garantida, uma vez que, além de depender financeiramente e tecnicamente do Estado, este não legítima o papel deste Comitê de deliberar sobre a gestão de recursos hídricos na $\mathrm{RH} 2$, tendo em vista que o exclui do processo de participação das decisões. Apenas quatro dos entrevistados acreditam na independência do Comitê para exercer suas atividades e três entrevistados preferiram não avaliar este requisito.

Para a maioria dos entrevistados $(66,67 \%)$, as responsabilidades do Comitê das Bacias Hidrográficas dos Rios Chapecó e Irani e seu mandato estão claramente definidos. No entanto, estas responsabilidades precisam ser respeitadas pelo Estado e internalizadas nas ações do Comitê, foi o que destacaram os $33,33 \%$ que atribuíram nota baixa para esta afirmativa.

Todos os membros entrevistados acreditam que os mecanismos vigentes de composição do Comitê das Bacias Hidrográficas dos Rios Chapecó e Irani atendem a escolha representativa das partes interessadas na gestão de recursos hídricos na RH2, ou seja, os membros acreditam que as partes estão corretamente representadas dentro desse, no entanto, alguns membros destacaram em seus comentários que é necessário criar mecanismos para estimular a participação dos membros e sugeriram que uma atuação mais efetiva pode representar um bom estímulo para aumentar a participação.

Ampliar e fomentar a participação de todos os segmentos no Comitê é primordial e representa um desafio a ser superado. Impulsionar a participação do poder público, especialmente, o municipal, tem sido um grande desafio na maioria dos $\mathrm{CBH}$ brasileiros (OLIVEIRA, 2011). Além disso, é necessário criar ferramentas para estimular uma maior participação da sociedade civil, tendo sido sugeridos instrumentos como educação continuada 
e a aprendizagem social (JACOBI, 2010). Acredita-se que estes instrumentos podem auxiliar para que os membros conheçam a realidade local e tenham capacidade crítica e condições de intervir no processo decisório, a partir do diálogo e da negociação.

Visando identificar a percepção dos membros a respeito da influência do referido Comitê na gestão de recursos hídricos no estado de Santa Catarina, observou-se que, para $88,94 \%$ dos entrevistados, o Comitê não influencia nessa gestão. Isto porque o comitê não tem sido incluído no processo decisório, nem exercido as funções para as quais foi constituído, encontrando-se ainda hoje em processo de estruturação.

Todos os membros destacaram que não tomam decisões, basicamente, porque as decisões não estão passando pelo Comitê, o que prejudica sua legitimidade, a participação e também sua continuidade. Os membros também destacaram que não recebem nenhum recurso para atuarem no Comitê e que estão ali porque acreditam que este órgão possa realmente contribuir para um processo mais democrático de gestão.

Por fim, observa-se que as críticas e as falhas do processo de governança de recursos hídricos na RH2 são bastante explícitas em relação a todos os princípios de governança elencados nesta pesquisa e ferem a eficácia, a eficiência e o comprometimento da governança local da água.

\section{Considerações Finais}

O estudo com o Comitê das Bacias Hidrográficas dos Rios Chapecó e Irani revela que, na prática, este grupo não consegue cumprir com suas prerrogativas legais e contribuir mais efetivamente para as decisões voltadas à gestão de recursos hídricos em Santa Catarina, reforçando a teoria de que no Brasil estes grupos apresentam muitas dificuldades para se organizarem como órgãos deliberativos e consultivos da gestão hídrica. Suas principais contribuições limitam-se a promover a educação ambiental dentro das bacias hidrográficas, a partir de alguns trabalhos com as comunidades locais, e a fomentar o debate mais participativo dentro dos referidos grupos, mas com baixo impacto decisório.

Salienta-se que esta realidade, além de prejudicar a gestão do território das bacias hidrográficas - território onde as relações de poder são permeadas pelas interações entre atores governamentais e não governamentais e por diferentes níveis de governo - exige, para que avanços ocorram, que estas interações sejam orientadas pelos princípios da eficácia e do comprometimento dos atores sociais e do Estado para mapear e preencher as lacunas, com vistas à uma gestão integrada dos recursos hídricos.

Entende-se que a constituição dos $\mathrm{CBH}$, como organismos de planejamento, gestão e regulamentação da gestão hídrica, envolve um sistema bastante complexo, no qual participam 
muitos atores públicos, privados e sociedade civil. Possuir um Estado forte (tecnicamente e financeiramente), capaz de implantar efetivamente a política pública e que dê suporte a este modelo, parece ser essencial, principalmente, por que a cultura brasileira ainda não está familiarizada com a existência da bacia hidrográfica como unidade de planejamento, nem mesmo com os modelos de descentralização das decisões e de participação.

Ainda, é preciso repensar o sistema brasileiro de gestão como um todo, revendo as capacidades técnicas de cada órgão que compõem o SINGREH, especialmente, os órgãos estaduais, para que este possam exercer competências técnicas mais efetivas, claras e confiáveis. Além disso, o SINGREH precisa ampliar a visibilidade do setor de recursos hídricos tanto para a sociedade, quanto para os governos estaduais, demonstrando que uma política mais efetiva, ou seja, baseada em resultados, poderá repercutir em melhores ganhos sociais, ambientais e econômicos para o País.

Os sistemas estaduais de gerenciamento hídrico no Brasil necessitam trabalhar para implementar e/ou fortalecer todos os instrumentos previsto na PNRH, tendo em vista que a efetiva utilização destas ferramentas possibilitará um maior empoderamento das instituições relacionadas à gestão hídrica, em especial, as secretarias estaduais de recursos hídricos e os $\mathrm{CBH}$. Estes necessitam aperfeiçoar as trocas de experiências, especialmente, entre os atores das bacias hidrográficas, a comunicação com a sociedade e com os demais órgãos públicos, sobretudo, os órgãos públicos locais (Ministério Público e Prefeitura) e a cooperação em rede, a fim de que as deliberações e ações propostas pelos grupos de bacias hidrográficas sejam efetivamente consolidadas na prática.

\section{Referências}

AGÊNCIA NACIONAL DE ÁGUAS - ANA. Cuidando das águas: soluções para melhorar a qualidade dos recursos hídricos. Programa das Nações Unidas para o Meio Ambiente. Brasília: ANA, 2011. Disponível em: 〈www.ana.gov.br〉. Acesso em: 14 abr. 2011.

BARDIN, L. Análise de conteúdo. Lisboa: 70, 2014.

CAMARGOS, L. de. M. M. Governança dos recursos hídricos: um estudo das percepções dos stakeholders sobre a gestão das águas no Estado de Minas Gerais. 2008. $127 \mathrm{f}$. Dissertação (Mestrado em Administração) - Fundação Mineira de Educação e Cultura, Belo Horizonte, 2008.

CAMPOS, V. N. de O.; FRACALANZA, A. P. Governança das águas no Brasil: conflitos pela apropriação da água e a busca da integração como consenso. Ambiente \& Sociedade, v. 13, n. 2, p. 365-382, jul./dez. 2010.

CASTRO, J.E. Water governance in the twentieth-first century. Ambiente \& Sociedade, v. 10, n. 2, p. 97-118, jul./dez. 2007.

CONSELHO ESTADUAL DE RECURSOS HÍDRICOS DO ESTADO DE SANTA CATARINA - CERHSC. Resolução CERHSC n. 03 de 23 de julho de 1997. Aprova as normas gerais para composição, organização, competência e funcionamento dos comitês de 
bacias hidrográficas. Florianópolis, 1997. Disponível em: <http://www.sirhesc.sds.sc.gov.br/sirhsc/>. Acesso em: 15 fev. 2015.

COSTA, M. A. M. Reflexões sobre a política participativa das águas: o caso $\mathrm{CBH}$ Velha/MG. 2008. 134 f. Dissertação (Mestrado em Geografia) - Universidade Federal de Minas Gerais, Belo Horizonte, 2008.

EMPRESA DE PESQUISA AGROPECUÁRIA E EXTENSÃO RURAL DE SANTA CATARINA - EPAGRI. Centro de Informações de Recursos Ambientais e de Hidrometeorologia de Santa Catarina - CIRAM. Mapas digitais de Santa Catarina. Florianópolis, 2010. Disponível em: <http://ciram.epagri.sc.gov.br/mapoteca/>. Acesso em: 24 nov. 2015.

FRACALANZA, A. P.; JACOB, A. M.; EÇA, R. F. Justiça ambiental e práticas de governança da água: (re) introduzindo questões de igualdade na agenda. Ambiente \& Sociedade, v. 16, n. 1, p. 19-38, jan./mar. 2013.

GAGG, M. Descentralização ou re-centralização? Uma análise do processo de implementação dos comitês de bacias hidrográficas do Paraná. 2014. 127 f. Dissertação (Mestrado em Administração) - Universidade de Londrina, Londrina, 2014.

GLOBAL WATER PARTNERSHIP - GWP. Effective water governance. Learning from the dialogues. 2003.2 Disponível em: $<$ http://www.gwpforum.org/gwp/library/Effective\%20Water\%20Governance.pdf $>$. Acesso em: 10 fev. 2016.

GOMES, C. S. Comitês de bacias hidrográfica de rios do Médio São Francisco: possibilidade e desafios de gestão do uso da água. 2008. 109 f. Dissertação (Mestrado em Administração) - Universidade Federal de Lavras, Lavras, 2008.

HEINELT, H., et al. (Eds.). Participatory governance in multi-level context. Opladen: Leske \& Budrich, 2002. p. 107-131.

HELD, D. Democracy and the global order: from the modern state to cosmopolitan governance. Cambridge: Polity Press, 1995.

HIRST, P. Associative democracy: new forms of economic and social governance. Cambridge: Polity Press, 1994.

INSTITUTO BRASILEIRO DE GEOGRAFIA E ESTATÍSTICA - IBGE. Censo Demográfico 2010. Rio de Janeiro: IBGE, 2010b. Disponível em: <http://www.censo2010.ibge.gov.br>. Acesso em: 15 nov. 2015.

JACOBI, P. R. Aprendizagem social, desenvolvimento de plataformas de múltiplos atores e governança da água no Brasil. INTERthesis, Florianópolis, v. 7, n. 1, p. 69-95, jan./jul. 2010.

. Governança da água no Brasil. In: RIBEIRO, W. (Org.). Governança da Água no

Brasil: uma visão interdisciplinar. São Paulo: Annablume/Fapesp/CNPq, 2009. p. 35-59.

JACOBI; SINISGALLI, P. A. de A. Governança ambiental e economia verde. Ciência \& Saúde Coletiva, v. 17, n. 6, p. 1469-1478, 2012.

KOOIMAN, J. Modern governance: new government-society interactions. Newbury Park, Calif.: Sage, 1993.

LIMA, A. J. R. Governança dos recursos hídricos: proposta de indicador para acompanhar sua implementação. São Paulo: WWF-Brasil; FGV, 2014.

MACHADO, J. B. Análise da governança das águas da Bacia Hidrográfica da Lagoa Mirim, extremo sul do Brasil. 2012. 205 f. Dissertação (Mestrado em Gerenciamento Costeiro) - Universidade Federal do Rio Grande do Sul, Porto Alegre, 2012.

MADRUGA, F. do. N. O papel dos comitês de bacias de Santa Catarina no Sistema Nacional e Estadual de Gerenciamento de Recursos Hídricos. 2007. 127 f. Dissertação (Mestrado em Geografia) - Universidade Estadual Paulista, Rio Claro, 2007.

MINAYO, M. C. S. O desafio do conhecimento: pesquisa qualitativa em saúde. 8. ed. São Paulo: Hucitec, 2004. 
MOREIRA, M. de. F. Comitês de bacias hidrográficas de Pernambuco: dificuldades, avanços e desafios. 2008. 173 f. Dissertação (Mestrado em Gestão e Políticas Ambientais) Universidade Federal de Pernambuco, Recife, 2008.

OLIVEIRA, R. de M. L. A criação dos Comitês de Bacias Hidrográficas do Rios Jacu e Santa Maria da Vitória: perspectivas e desafios da gestão hídrica capixaba. 2011. $311 \mathrm{f}$. Dissertação (Mestrado em Geografia) - Universidade Federal do Espírito Santo, Vitória, 2011.

ORGANIZAÇÃO PARA A COOPERAÇÃO E DESENVOLVIMENTO ECONÔMICO OCDE. Governança dos Recursos Hídricos no Brasil. Paris: OECD Publishing, 2015. Disponível em: 〈http://dx.doi.org/10.1787/9789264238169-pt>. Acesso em: 6 jan. 2016.

. Guidelines on the corporate governance of state-owned enterprises. 2005. Disponível em: <http://www.oecd.org/corporate/ca/corporategovernanceofstateownedenterprises/42524177.pdf>. Acesso em: 27 fev. 2014..

Water Governance in OECD Countries: A Multi-level Approach. Paris: OECD Publishing, Paris, 2011. Disponível em: <http://dx.doi.org/10.1787/9789264119284-en>. Acesso em: 6 jan. 2016.

PEREIRA, R. M. V.; MEDEIROS, R. A. Aplicação dos instrumentos de gestão e do Sistema de Gerenciamento dos Recursos Hídricos na Lagoa Rodrigo de Freitas, RJ, Brasil. Ambiente \& Água, v. 4, n. 3, p. 211-229, 2009.

RAHAMAN, M. M.; VARIS, O. Integrated water resources management: evolution, prospects and future challenges. Sustainability: Science, Practice, \& Policy, Bethesda, v. 1, n. 1, p. 15-21, 2005.

RIBEIRO, W. C. Impasses da governança da água no Brasil. In: RIBEIRO, W. (Org.). Governança da Água no Brasil: uma visão interdisciplinar. São Paulo: Annablume/Fapesp/CNPq, 2009, p. 111-133.

RICHARDS, D.; SMITH, M. J. Governance and public policy in the United Kingdom. New York: Oxford University Press, 2002.

SANTA CATARINA (Estado). Decreto Estadual n. 3.498, de 8 de setembro de 2010. Cria o Comitề de Gerenciamento das Bacias Hidrográficas dos Rios Chapecó e Irani e Bacias Hidrográficas Contíguas - Comitê̂ Chapecó/Irani. Florianópolis, 2010. Disponível em: <http://www.aguas.sc.gov.br/jsmallfib_top/Comite\%20Rio\%20Chapeco\%20e\%20Irani/Legisl acoes/Comite/decreto\%20de\%20criacao/DECRETO\%20Nro3.pdf>. Acesso em: 2 fev. 2013.

SECCHI, L. Modelos organizacionais e reformas da administração pública. Revista de Administração Pública, v. 43, n. 2, p. 347-369, mar./abr. 2009.

TRINDADE, L. L. de. Gestão integrada de bacias hidrográficas: papel, potencialidades e limitações do comitês de bacias hidrográfica.. 2016. 269 f. Tese (Doutorado Interdisciplinar em Ciências Humanas ) - Universidade Federal de Santa Catarina, Florianópolis, 2016.

YIN, R. K. Estudo de caso: planejamento e métodos. 4. ed. Porto Alegre: Bookman, 2010.

Recebido em 25 de outubro de 2017.

Aceito em 27 de março de 2018. 